\title{
THE TWO CULTURES
}

\section{SCIENTISTS AND JOURNALISTS, NOT AN OUTDATED RELATIONSHIP}

\author{
HANS Peter Peters
}

The relationship between scientists and journalists is much better than its image would suggest. Scientists not only believe that public communication is a duty, but also that media visibility is beneficial. Scientific culture differs from that of journalism, which causes partially discrepant expectations; but in most cases these do not preclude satisfying interactions between journalists and scientists. The traditional relationship between science and journalism is challenged by the rise of new online media. These provide opportunities for scientists and scientific organizations to communicate directly with the public via websites, blogs and social networks. Science journalism may be entering a critical period but it is unlikely that it will fall into decline or be replaced by these new science communications media.

Keywords: science journalism, scientists, journalists, new media, science in society.

The development of modern academic scholarship leads to differentiation from the general social context in several dimensions. There is, first, the social organization of scientific research, resulting in the establishment of research institutes and laboratories, professional roles, scientific associations, scientific journals, the institution of peer review, and a specific ethos of science (Merton, 1957: 552-561). One characteristic of this system of science is its insistence on epistemic autonomy and peer orientation: scientists are supposed to decide whether a peer's work rates as good or bad science - not the user of scientific results, not the funder, not those in power. Like other professions, academic disciplines are anxious to regulate access to their communities, expecting formal training and academic degrees by candidates. Furthermore, they socialize their new members into the professional culture keeping non-members out of science or assigning them marginal roles at best, for example as amateur scientists.

A second aspect of how science is detached from laypeople's everyday world concerns the construction of scientific knowledge as «special knowledge», i.e., of knowledge that not everybody is expected to master. This relieves scientists from expectations of general comprehensibility in their peer-to-peer communications. Scientific knowledge nowadays is often so esoteric that it is largely incomprehensible to outsiders, even for scientists from other disciplines. For non-scientists, access to such knowledge is only possible in a metaphoric way and to a certain degree.

The emergence of modern science is thus related to the construction of a boundary, distinguishing the scientific from the non-scientific domain. On the one hand, this boundary protects the knowledge creation process against «corrupting» external influences of, for instance, money, political power or political correctness. On the other hand, the boundary creates a barrier for communication and collaboration across the borders of science. Thus science and other areas of society need to maintain a delicate balance between defending and accepting the relative autonomy of science, and enabling communication and collaboration across the frontiers of the scientific realm. The existence of such a border and the emergence of a specific scientific culture are consequences of the functional differentiation 


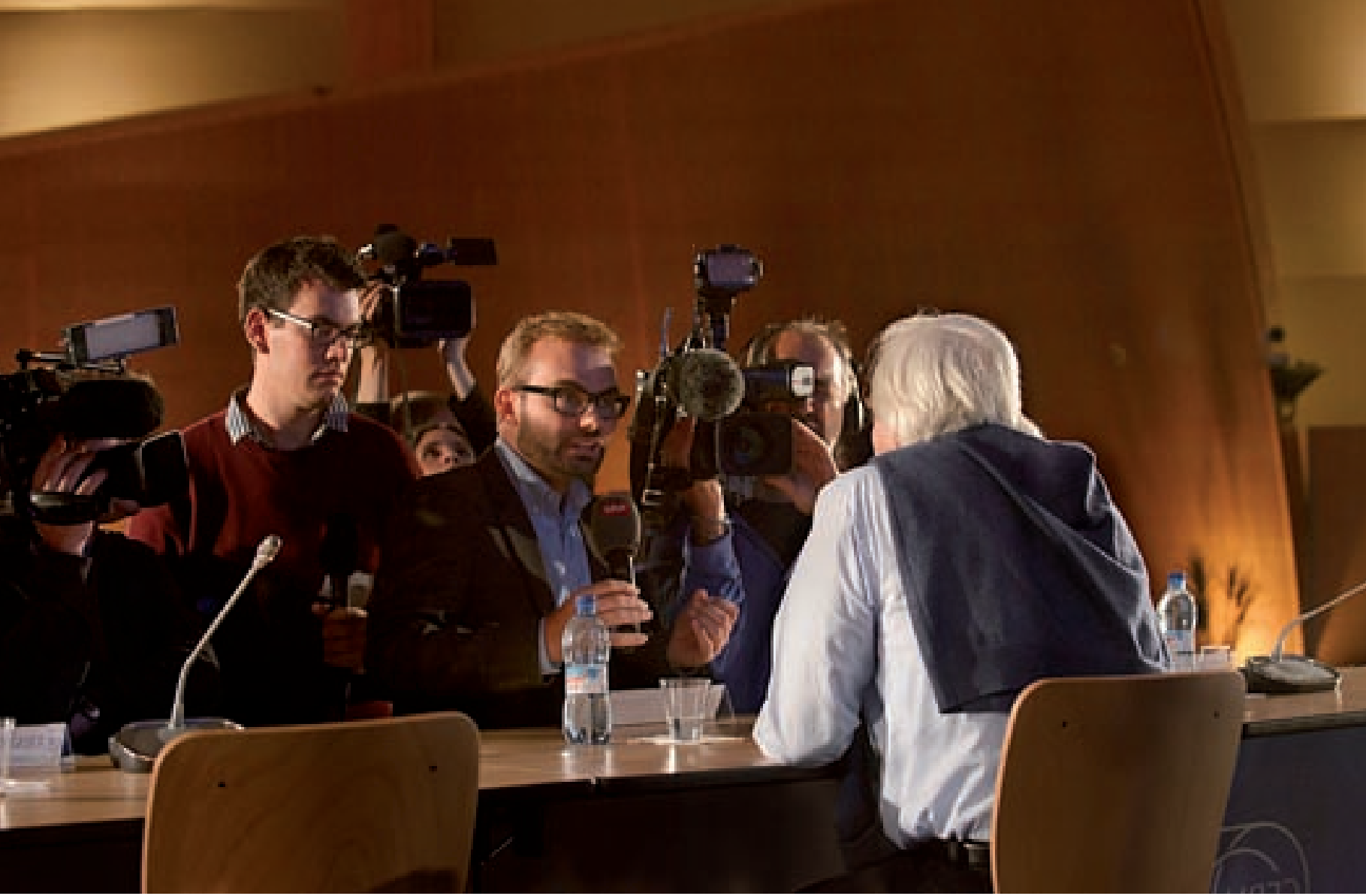

Scientists may think of public communication as a form of teaching students. This conception is the core of the "popularization" paradigm. But science communication is often carried out strategically as "public relations for science and technology". Above, Rolf Heuer, general manager at CERN, during a press conference to announce the 2013 Nobel Prize for Physics winners, Higgs and Eglert.

of modern societies by which certain functions are delegated to specific subsystems operating by their own rules and norms.

Popular scientific communication is a specific case of a boundary-crossing activity. From the point of view of scientists, communication with the general public can be conceptualized in several ways. Scientists may think of it as a kind of socialization of non-scientists into science, i.e., as a «diluted» form of teaching students. This conception is the core of the «popularization» paradigm. Consequently, the goal of this paradigm is turning laypeople into quasiscientists as far as possible. In his early survey of 255 full professors at the University of Mainz, Germany, Krüger (1985) found that two thirds of them agreed with the statement «Science reporting is "lecturing" in a broader sense». Obviously, for many academics the idea of communicating via the general mass media resembles their familiar concept of teaching students.

Another way for academic researchers to conceptualize their relationship with a general lay audience is in terms of an advisory model. Scientists in the fields of health, risk and environment, for example, may feel motivated to advise lay audiences regarding healthy, safe and environmentally friendly behaviour, or on the availability of therapy options for diseases. Researchers from humanities and social sciences who advise on the education of children, political decisions or consumer trends, for example, also assume the role of a «public expert». In a recent study, 1,069 German researchers were asked about the topic of their most recent talk with a journalist. Almost half of them (44\%) indicated that their last interview had not focused on research or its applications but on "general expertise on a certain topic, event or problem». The «expert» role was more common among researchers from the humanities and social sciences than for those from science and engineering (Peters, 2013).

And finally, scientists may think of public communication of science strategically as «public relations for science and technology». Nelkin (1987) 
and Weingart (2001), for example, have pointed to the increasing relevance of the mass media for the public legitimacy of science and technology, and the resulting adaptation of scientists and scientific organizations to the rules of the media. Acceptance of disputed scientific theories (e.g., human evolution, global climate change), morally challenged scientific practices (e.g., animal experimentation, human embryonic stem cell research)

and science-based risk

technologies (e.g., nuclear power,

GM food, nanotechnology), as well as funding and other societal support of more basic science are seen - probably correctly - as dependent on public visibility and image. Scientists almost universally assume that public rejection of science results from a lack of knowledge, and that informing a general audience about science and technology will enhance their public acceptance. In a number of surveys of scientists in North and South America, in Europe and in Asia, respondents tended to agree strongly with the items «If the public only knew more about research, it would be more positive about science» and «Greater

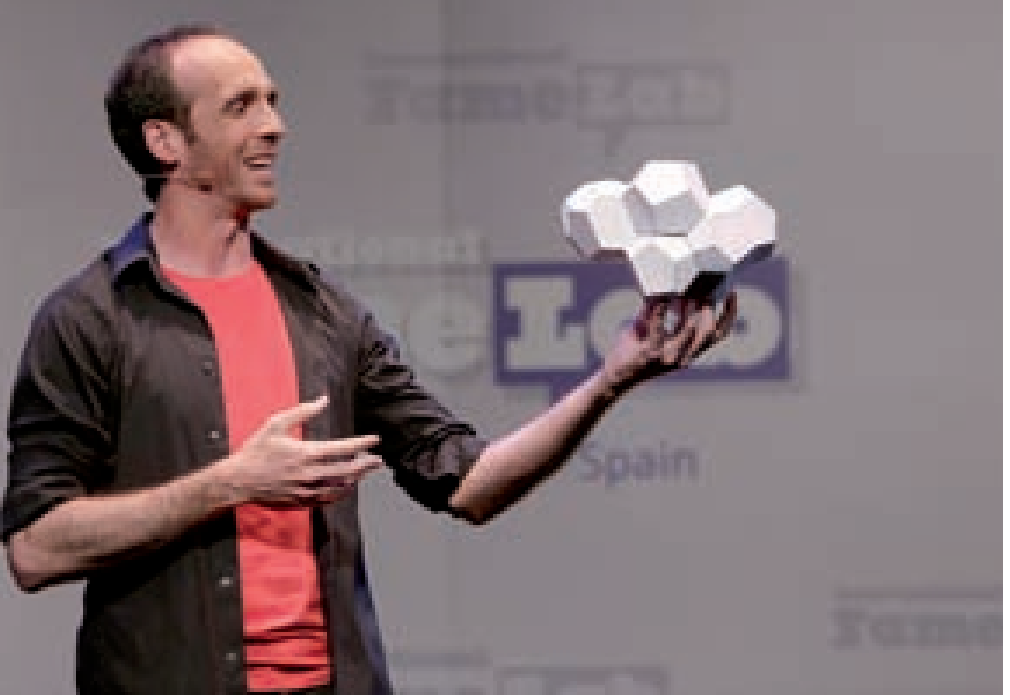

Despite the growing efforts for direct and dialogic interaction with the public in science festivals, science cafés and consensus conferences, for example, public communication of science and technology in our societies is mainly mass-mediated. Above, mathematician Eduardo Sáenz, winner of the I National Scientific Talks Competition Famelab, currently a member of the scientific stand-up group The Big Van Theory. knowledge on the part of the public leads to more positive attitudes toward science and technology». ${ }^{1}$

It is quite common for scholars of science communication to criticize this so-called «deficit model» and to emphasize that it is empirically false and normatively unacceptable as it leads to a negative stereotype of the public as cognitively deficient.

Ironically, this model may have positive implications, though, as it motivates scientists to focus on «knowledge» in their communication efforts.

Despite the growing efforts towards direct and dialogic interaction with the public in science festivals, science cafés and consensus conferences, for example, public communication of science and technology in our societies is mainly massmediated. Scientists' responses to the item that scientists should «place more emphasis on personal encounters and dialogue with citizens rather than on media such as publications, Internet, radio and television» are at best ambivalent - with a tendency towards the negative (Peters, 2013). And more specifically, despite the current hype about «new media» such as blogs and social networks, the majority of scientists still consider journalistic media - printed newspapers and magazines, radio and TV, and the online spin-offs of these media - as the main communication channels with the general public (Allgaier et al., 2013a).

But we cannot ignore the huge changes in communications brought on by the proliferation of the Internet and of mobile devices such as smart phones and tablets. Journalistic content in the online environment may change its form - become more interactive by integrating user-produced content or adopt the blog format, for example. It may be disseminated, highlighted and commented on in a variety of ways on Twitter, Facebook or blogs, and linked to non-journalistic information sources. Furthermore, journalists will use scientist-generated content found in blogs and social media as source material. But in the end the question is who will produce the «stories» that make scientific knowledge accessible to the public. Writing stories that attract general interest and are broadly comprehensible is not a trivial task. This question has several aspects: about

${ }^{1}$ Results of surveys in Germany, France, UK, USA and Japan are shown in Peters (2013); similar results of surveys in Brazil, Taiwan and China Mainland are still in press. 
motivation, competence and available resources such as time and money.

Scientists have a strong preference to control journalistic science reporting, indicated by their request that journalists should let them check the stories in which they are quoted prior to publication - a request that many journalists reject (Peters, 1995; Gunter et al., 1999; Chen, 2011). For a long time, scientists have dreamt of addressing the public directly without having to go through journalists. In 1984, when discussion arose on the introduction of cable TV in Germany, about half of the German university professors surveyed by Krüger (1985) indicated that they would like to be directly involved in a cable TV channel while only $7 \%$ considered science reporting as an exclusive task of journalists. There is still moderate support among German scientists for the demand that «science should use its own information sources, such as publications, websites and blogs, to address the public instead of relying on journalists to disseminate information» (Peters, 2013). Today's online media environment provides much wider opportunities than in the past to address a general audience directly, as shown by blogging scientists.

It seems unlikely that in addition to their work as researchers, lecturers, research managers and

\section{«SCIENTISTS ASSUME THAT INFORMING} A LAY AUDIENCE ABOUT SCIENCE AND TECHNOLOGY WILL IMPROVE PUBLIC ACCEPTANCE»

members of advisory committees the majority of scientists will be eager to adopt the production of content for the general public as a new routine duty. In a study based on semi-structured interviews with neuroscientists in Germany and the United States, most interviewees considered communication with the lay public to be a moral duty and a strategic necessity; but some also considered it to be a distraction from their genuine work (Allgaier et al., 2013b). Several interviewees explained how they tried to organize public communication in an efficient, time-saving way by focusing on key media or by delegating certain tasks to communication professionals: public relations departments of their organizations or even commercial communication agencies. Most researchers are in favour of public communication

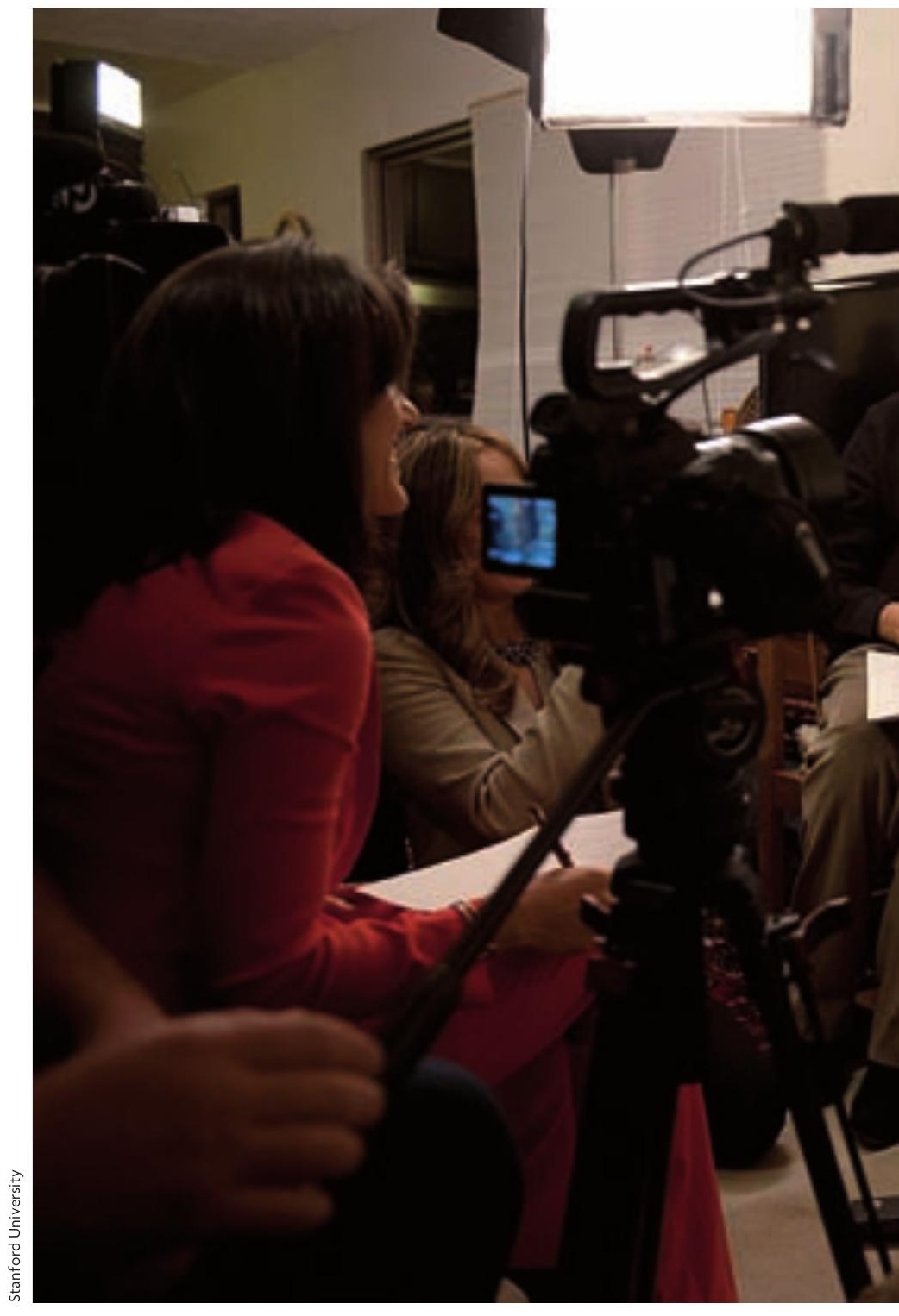

and are prepared to become personally involved, but in practice they rely on mediators such as public information officers and journalists - assuming the role of an «information source».

Journalism is not just a mediator between science and the public in terms of dissemination or translation. Following Kohring's (1997) systemstheoretical conceptualization of science journalism, journalism (like science) is a functionally differentiated social subsystem with a specific function. Its function is to «observe» the different segments of society such as politics, economy, sport, art and science, based on criteria of general relevance, and to provide the result of this observation as a common reference of actors from different segments 


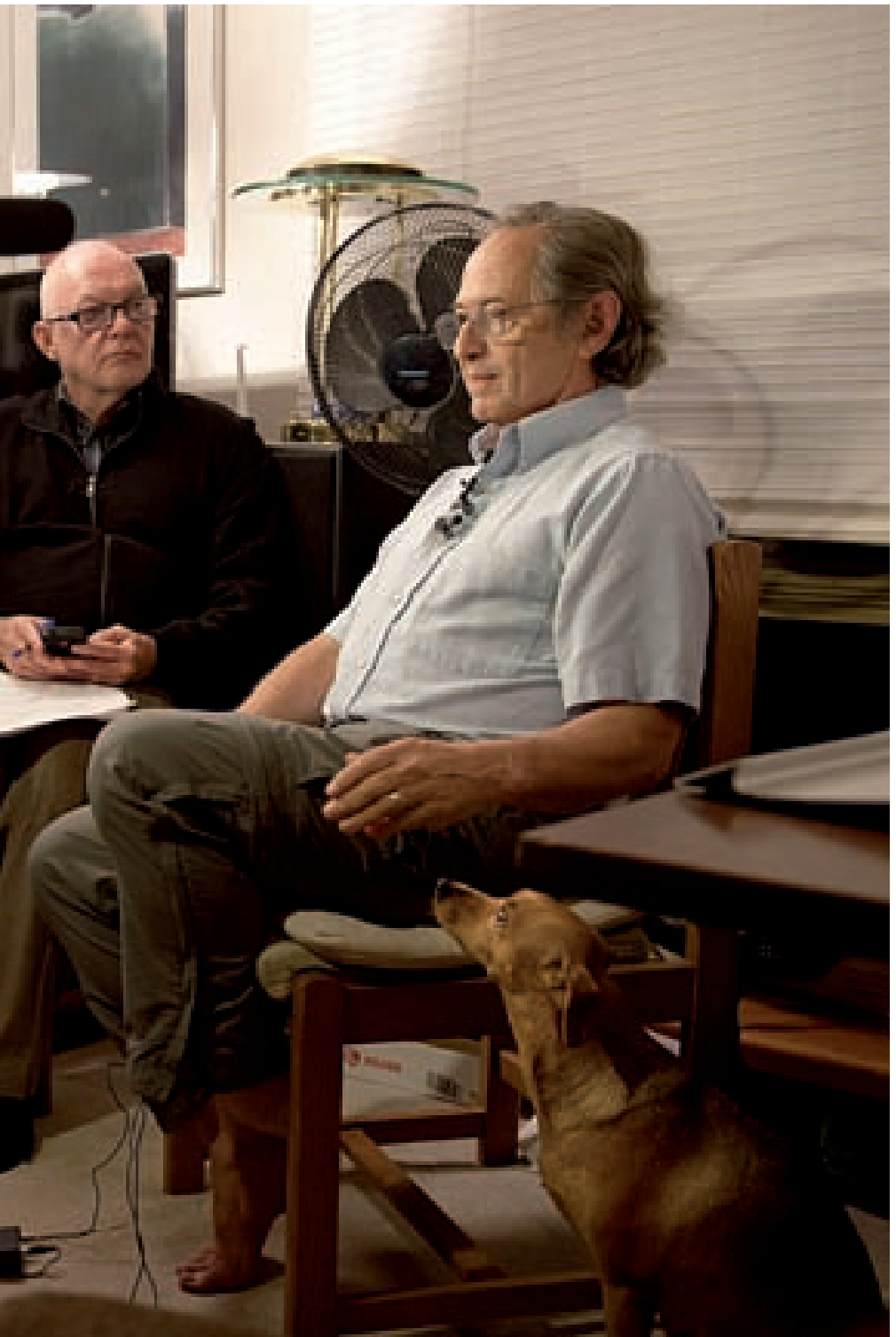

2013 Nobel Prize for Chemistry winner, Michael Levitt, is interviewed after the award was announced. Generally, scientists perceive career benefits resulting from visibility in the media, and consider their experiences with journalists good.

\author{
«FOR MANY ACADEMICS THE IDEA OF \\ COMMUNICATION VIA THE GENERAL \\ MASS MEDIA RESEMBLES THEIR \\ FAMILIAR CONCEPT OF UNDERGRADUATE \\ TEACHING»
}

of society. Via its selection of topics, actors and viewpoints, journalism marks these as «relevant to society». It creates a common social reality that balances the tendency of the subsystems to apply their specific perspectives, which may be incompatible with each other. To serve as credible «authority on social relevance» journalism has developed a set of professional routines, selection criteria, quality criteria and reporting formats - a journalistic culture. It is imparted to students in journalism programmes, nurtured in journalists' associations and reinforced by awards like the Pulitzer Price.

There is concern about a «gap» or a «distance» between science and journalism. Theoretically, one may consider interactions between scientists and journalists in several ways: as intercultural communication with potential value-related conflicts and misunderstandings; as communication between players using different «codes» (truth vs. broad social relevance); or as a conflict of interests, with the scientist's goal being one of accurate and positive coverage vs. the journalist's goal being to attract an audience. Empirically, we can indeed find mismatches between normative expectations of scientists and journalists regarding their interactions. In two German surveys, scientists and journalists who had interacted in reporting on risk and climate change, responded to the same sets of items.

The analysis revealed five areas of discrepancies (Peters, 1995; 2008): (1) Scientists as well as journalists aimed at controlling the coverage; (2) Scientists more than journalists perceived criteria of scientific communication as also relevant for public communication; (3) Scientists more than journalists considered journalism as a service for science; (4) Journalists more than scientists emphasized a critical function of journalism towards science; (5) Scientists showed stronger paternalism towards the media audience than journalists.

A general and conclusive assessment of the quality of the relationship between scientists and journalists is difficult. First, as studies have shown, the nature of this relationship varies by country and research field, and despite the number of studies, their cultural and disciplinary range is still limited. Second, a systematic evaluation of the science-journalism relationship would require a set of normative criteria against which to measure current practices. The development and justification of such a set of normative criteria - based on professional ethical reasoning rather than on researchers' gut feelings or on the subjective satisfaction of communication partners - is not a trivial task and has yet to be 


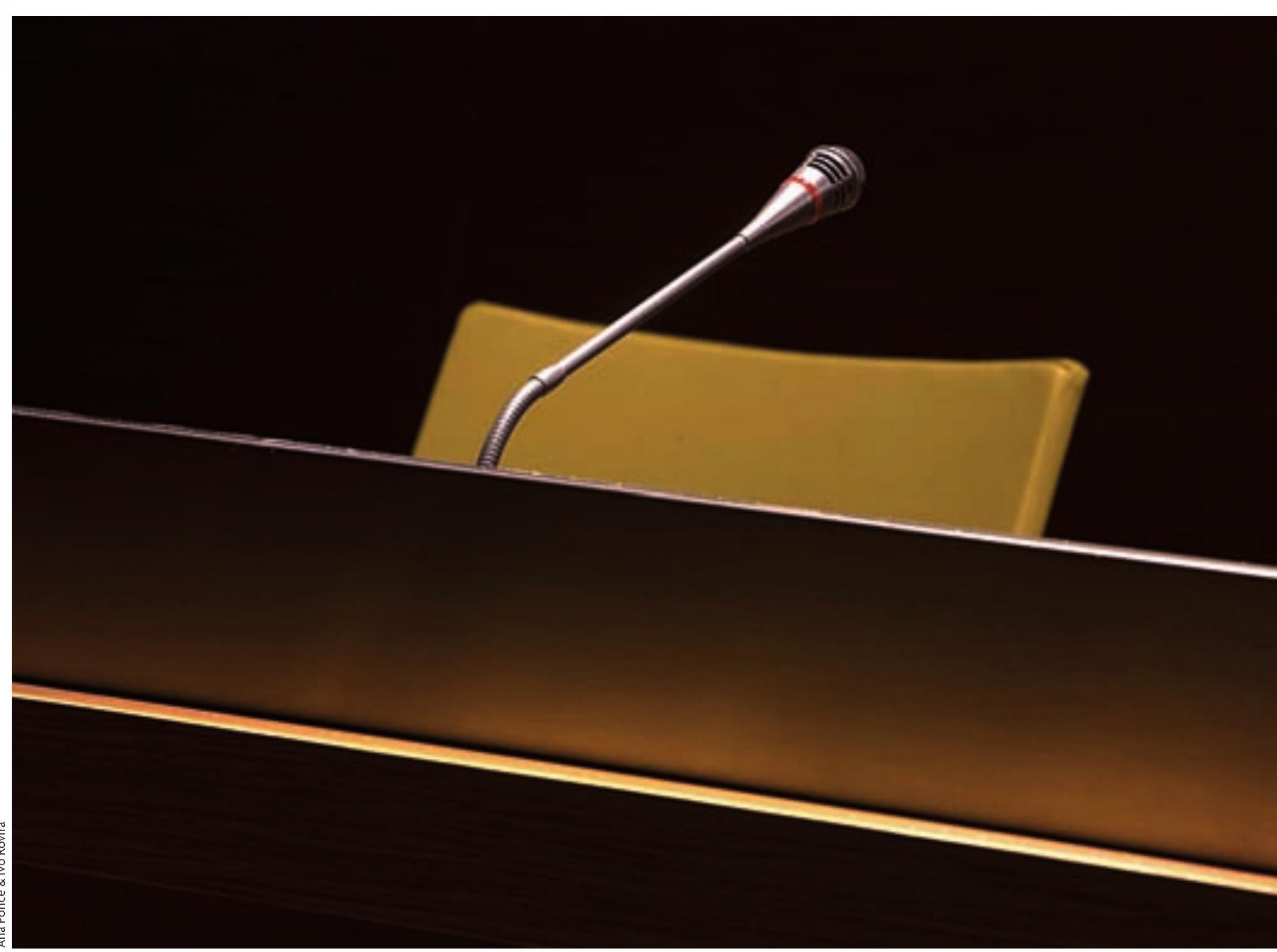

Popularization of science is a specific case of a boundary-crossing activity. Science and the other parts of society thus need to maintain a delicate balance between defending or accepting relative autonomy of science and enabling communication and collaboration across the border of the scientific realm.

done. The following description of the state of the relationship does therefore not constitute a valid normative assessment. It shows that many scientists are actually communicating via the mass media and that their interactions with journalists are mostly smooth. The analysis is limited in several respects. It does not look at the role of highly visible science popularizers such as Juan Luis Arsuaga, Eduard Punset or Ramon Folch in Spain (cf. GarcíaMestres et al., 2012) or at science communication in controversial fields, but rather focuses on the routine interactions between scientists and journalists.

Occasional conflicts arise between scientists and journalists, but in general scientists are satisfied with their experiences as information sources for journalists. In surveys conducted in several countries in Europe, North America, South America and Asia, most scientists rated their experiences with journalists as «mostly good», some reported mixed or neutral experiences and very few rated them as «mostly bad». Furthermore, many of the surveyed scientists perceived career benefits from visibility in the media while very few felt that their career had been damaged by media reports. The surveys also showed that scientific communities and research organizations have certain normative expectations of how scientists should interact with the media. Yet, most scientists reported encouragement from their respective research institutions, and most of them said that they had received positive or neutral, but hardly any critical feedback from peers and superiors after media exposure. Despite potential conflicts with 
journalists, the frequent experience of (mostly minor) inaccuracies in the coverage, and the risk of annoying peers, supervisors and press officers, in most cases scientists classify their interaction with journalists as satisfactory. ${ }^{2}$

Science journalism seems to be in crisis; however, reporting patterns are changing in favour of online sources, the online market is wide open to all types of competing content providers, and the economic basis of quality print journalism - based on subscriptions and newsstand sales - is being undermined because these payment models prove difficult to transfer to the online environment (Brumfiel, 2009). Nevertheless, it is unlikely that science journalism will die out because its core function can hardly be substituted by alternative forms of public communication. While dissemination of popularized scientific knowledge can take place in many communication settings, those based on self-presentation of science (like in science blogs and science public relations) cannot credibly substitute journalism as external observation of science. The rigid selection of events, actors and claims for coverage by professional journalism, based on anticipated relevance for an audience of non-scientists, can only be simulated by communicators from inside science.

One may expect that the role of author will become relatively more important for scientists in the course of this development and, conversely, their role as information source for journalism will become less important. How likely is that? First of all, we have to acknowledge that scientists have always been authors in the public realm. They have published popular science books, written articles for Mètode, contributed their professional image to brochures, and been invited to air their views as guest authors in newspapers and magazines. The advantage of being authors for scientists is that they have more control of the timing and content of publication than they do as sole information sources. But the need to create an audience and produce the content requires communication competence and time; it cannot be done casually. As demonstrated, scientists are quite

\footnotetext{
${ }^{2}$ This paragraph summarizes results from several scientists' surveys in Germany, France, UK, USA, Brazil, Japan, Taiwan and China Mainland. Some results are published in Peters et al. (2008) and Peters (2013); other results are still unpublished.
}

successful as information sources and may cherish the «recognition as relevant» implied by journalistic selection. «Scientists as information sources of journalists» is not an outdated relationship. Many, if not most, scientists will be satisfied with their role as information source; others will aim high and endeavour to enter the public communication field as authors.

\section{REFERENCES}

Allgaier, J.; Dunwoody, S.; Brossard, D.; Lo, Y.-Y. and H. P. Peters, 2013a. «Journalism and Social Media as Means of Observing the Contexts of Science». BioScience, 63: 284-287. DOI: <10.1525/ bio.2013.63.4.8>

Allgaier, J.; Dunwoody, S.; Brossard, D.; Lo, Y.-Y. and H. P. Peters, 2013b. «Medialized Science? Neuroscientists' Reflections on Their Role as Journalistic Sources». Journalism Practice, 7: 413-429. DOI: $<10.1080 / 17512786.2013 .802477>$.

BRUMFIEL, G., 2009. «Science Journalism: Supplanting the Old Media?». Nature, 458: 274-277. DOI: $<10.1038 / 458274 \mathrm{a}>$.

CHEN, Y.-N. K., 2011. «An Explorative Study on the Differences of the Two Profession's Perceptions of Science News» [in Chinese]. Chinese Journal of Communication Research, 19: 147-187.

García-Mestres, M.; Mateu, A. and M. DomínGUEZ, 2012. «La percepción social de los principales divulgadores españoles de la ciencia». Estudios sobre el Mensaje Periodístico, 18: 757-767. DOI: <10.5209/ rev_ESMP.2012.v18.n2.41044>.

GUNTER, B., KINDERLERER, J. and D. BeYLeVeld, 1999. «The Media and Public Understanding of Biotechnology: A Survey of Scientists and Journalists». Science Communication, 20: 373-394. DOI: $<10.1177 / 1075547099020004002>$

KoHRING, M., 1997. Die Funktion des Wissenschaftsjournalismus: ein systemtheoretischer Entwurf. Westdeutscher Verlag. Opladen.

KRÜGER, J., 1985. Wissenschaftsberichterstattung in aktuellen Massenmedien aus der Sicht der Wissenschaftler. Ergebnisse einer Befragung der Professoren der Johannes Gutenberg-Universität. [Unpublished thesis] University of Mainz. Mainz.

Merton, R. K., 1957. Social Theory and Social Structure. The Free Press. Glencoe, IL.

Nelkin, D., 1987. Selling Science: How the Press Covers Science and Technology. W.H. Freeman. New York.

Peters, H. P., 1995. «The Interaction of Journalists and Scientific Experts: Co-operation and Conflict between Two Professional Cultures». Media Culture \& Society, 17: 31-48. DOI: <10.1177/016344395017001003>.

Peters, H. P., 2008. «Erfolgreich trotz Konfliktpotential - Wissenschaftler als Informationsquellen des Journalismus». In HeTTWER, M. et al. (eds.). Wissenswelten: Wissenschaftsjournalismus in Theorie und Praxis. Verlag Bertelsmann Stiftung. Gütersloh.

Peters, H. P., 2013. «Gap between Science and the Media Revisited: Scientists as Public Communicators». Proceedings of the National Academy of Sciences, 110: 14102-14109. DOI: <10.1073/ pnas.1212745110>

PeTERS, H. P. et al., 2008. «Science Communication: Interactions with the Mass Media». Science, 321: 204-205. DOI: <10.1126/science.1157780>.

WeINGART, P., 2001. Die Stunde der Wahrheit? Zum Verhältnis der Wissenschaft zu Politik, Wirtschaft und Medien in der Wissensgesellschaft. Velbrück Wissenschaft. Weilerswist.

Hans Peter Peters. Communication researcher at Forschungszentrum Jülich and professor of Science Journalism. Free University of Berlin (Germany). 